\title{
Uso da haptoglobina como biomarcador para detecção de doença respiratória em bezerras Holandesas
}

Jean Silva Ramos ${ }^{[]^{\circ}}$, Karina Medici Madureira ${ }^{[b]}$, José Eugênio Guimarães ${ }^{[b]}$, Karen Nascimento da Silva ${ }^{[a]}$, Camila Costa Baccili[i], Camila Cecília Martin ${ }^{[a]}$, Natália Sobreira Basqueira ${ }^{[a]}$, Viviani Gomes ${ }^{[a]}$

\footnotetext{
[a] Faculdade de Medicina Veterinária e Zootecnia, Universidade de São Paulo (USP), São Paulo, SP, Brasil

${ }^{[b]}$ Escola de Medicina Veterinária e Zootecnia, Universidade Federal da Bahia (UFBA), Salvador, BA, Brasil
}

*Autor correspondente

e-mail: jeanramos4@usp.br

\section{Resumo}

A haptoglobina (Hp) é uma proteína de fase aguda que tem sido utilizada como biomarcador para o monitoramento da saúde em bovinos, entretanto sua viabilidade para a detecção de doenças na criação de bezerras tem sido pobremente explorada. Assim, o objetivo deste estudo foi avaliar o uso da haptoglobina como biomarcador de doença respiratória em bezerras. Foram selecionadas 95 bezerras Holandesas, entre 15 e 65 dias de vida, provenientes de duas fazendas de alta produção localizadas em São Paulo. Estes animais foram distribuídos em dois grupos de acordo com a ausência $(n=70)$ ou presença de doença respiratória ( $\mathrm{n}=25$ ). Bezerras diagnosticadas com outras enfermidades foram excluídas deste estudo. A doença respiratória foi detectada utilizando-se o escore padronizado pela Universidade de Wiscosin-Madison. Para tanto, foram atribuídas pontuações de 0 a 3, de acordo com a gravidade, considerando-se os seguintes parâmetros: temperatura, tosse, secreção nasal, secreção ocular e posicionamento das orelhas. 0 somatório dos escores permitiu classificar os animais em dois grupos distintos: saudável - escore respiratório $<4,0$; broncopneumonia - escore $\geq 4,0$. A Hp sérica foi dosada por técnica espectrofotométrica. A concentração de Hp para as bezerras saudáveis foi de 1,7 $\pm 1,93 \mathrm{mg} / \mathrm{dL}$, enquanto que as doentes apresentaram valores médios de 2,13 $\pm 2,12 \mathrm{mg} / \mathrm{dL}$ ( $\mathrm{P} \geq 0,05$, teste t-Student). No entanto, quando avaliou-se cada parâmetro individualmente, verificou-se diferença nos valores de Hp de acordo com a intensidade da tosse pelo teste one-way ANOVA ( $\mathrm{P}=0,013)$. As comparações múltiplas (post-hoc Bonferroni) entre os diferentes escores de tosse revelou diferenças entre os valores médios de Hp entre escore $0(1,36 \pm 0,52 ; \mathrm{P}=0,009 ; \mathrm{n}=52) \mathrm{e}$ escore $1(2,13 \pm 0,52 \mathrm{mg} / \mathrm{dL} ; \mathrm{n}=29)$. Os escores 2 e 3 não apresentaram diferenças com os demais $(3,17$ $\pm 5,8 \mathrm{mg} / \mathrm{dL} ; \mathrm{n}=9$ e $1,31 \pm 0,47 \mathrm{mg} / \mathrm{dL} ; \mathrm{n}=5$, respectivamente). Em relação ao escore de secreção nasal, observou-se maiores concentrações de Hp nas bezerras com escore $1(3,13 \pm 4,73 \mathrm{mg} / \mathrm{dL}, \mathrm{n}=13)$ em relação 
àquelas com escore $0(1,59 \pm 1,04 \mathrm{mg} / \mathrm{dL}, \mathrm{n}=71, \mathrm{P}=0,09)$. Os escores 2 e 3 não apresentaram diferenças com os demais $(1,15 \pm 0,27 \mathrm{mg} / \mathrm{dL}, \mathrm{n}=4$ e $1,39 \pm 0,72 \mathrm{mg} / \mathrm{dL}, \mathrm{n}=7$, respectivamente). Não foi possível detectar diferenças estatísticas entre os escores para temperatura, secreção ocular e posicionamento de orelhas, porém altos valores de $\mathrm{Hp}$ foram observados para o escore 3 de temperatura $\geq 39,4{ }^{\circ} \mathrm{C}(4,25 \pm$ $7,07 \mathrm{mg} / \mathrm{dL}, \mathrm{n}=6)$ e escore 2 para o posicionamento de orelhas $(18,63 \mathrm{mg} / \mathrm{dL}, \mathrm{n}=1)$. 0 baixo número de amostras e a grande variação nos teores de Hp nas pontuações 0 a 3 em cada parâmetro comprometeu a obtenção de resultados significativos. Os maiores valores de Hp nas bezerras com tosse induzida (escore 1) e secreção nasal sero-mucosa (escore 1) podem indicar processo inflamatório agudo. A intensificação do quadro clínico provavelmente está associada a inflamações crônica, justificando-se os baixos valores de Hp observados para a maioria dos parâmetros escores 2 e 3 . 